\title{
Safety and Efficacy of Circumcision Stapler in the Treatment for Children with Phimosis and Redundant Prepuce
}

\author{
Zhuocheng Jiang1,2, Hui Chen ${ }^{*}$, Mingli $\mathrm{Wu}^{2}$, Ping $\mathrm{Li}^{2}$, Hong Li², Mantao Jiang², Xingtao Cai ${ }^{2}$ \\ ${ }^{1}$ Department of Urology, Guangdong Provincial Work Injury Rehabilitation Hospital, Guangzhou, China \\ ${ }^{2}$ Department of Surgery, The Second People's Hospital of Baiyun District, Guangzhou, China \\ Email: *doc.chenhui@163.com
}

How to cite this paper: Jiang, Z.C., Chen, H., Wu, M.L., Li, P., Li, H., Jiang, M.T. and Cai, X.T. (2018) Safety and Efficacy of Circumcision Stapler in the Treatment for Children with Phimosis and Redundant Prepuce. Open Journal of Urology, 8, 263-266.

https://doi.org/10.4236/oju.2018.89029

Received: July 22, 2018

Accepted: August 27, 2018

Published: August 30, 2018

Copyright $\odot 2018$ by authors and Scientific Research Publishing Inc. This work is licensed under the Creative Commons Attribution International License (CC BY 4.0).

http://creativecommons.org/licenses/by/4.0/

\begin{abstract}
Objective: To observe the clinical effect and safety of circumcision stapler in children with phimosis and redundant prepuce. Methods: From July 2013 to July 2017, 40 children were prospectively randomized and assigned to experiment group (circumcision stapler $\mathrm{n}=20$ ) or control group (conventional circumcision, $n=20$ ). Outcomes were operation time, intraoperative blood loss and postoperative complications. Results: There was significant difference between the two groups for operation time $(5.35 \mathrm{~min}$ vs $30.30 \mathrm{~min}, \mathrm{P}<$ $0.05)$ and intraoperative blood loss $(2.56 \mathrm{ml}$ vs $10.40 \mathrm{ml}, \mathrm{P}<0.05)$ respectively. Conclusion: Circumcision staplers are superior to conventional circumcision for the advantages of shorter operation time and fewer blood losses.
\end{abstract}

\section{Keywords}

Circumcision Stapler, Children, Phimosis, Redundant Prepuce

\section{Introduction}

Phimosis and redundant prepuce is the common diseases with incidence of $8 \%$ in 4 - 7 years old boys [1]. The benefits of circumcision were highlighted, including reduced risk of penile cancer and reduced risk of human immunodeficiency virus infection [2]. The conventional circumcision as a golden standard surgery is widely performed. Unfortunately, it still has such disadvantages including adverse complications, inevitably suturing the incision, and cumbersome surgical procedure. Clinically, the circumcision stapler is widely used across the world for circumcision in adult and is associated with the advantages of a short operating time, an obvious effect and few complications. Therefore, 
this trail was to assess the clinical effect and safety of circumcision stapler in children with phimosis and redundant prepuce.

\section{Materials and Methods}

From July 2013 to July 2017, children with phimosis and redundant prepuces were recruited and assigned to experiment group (circumcision stapler) or control group (conventional circumcision) in the department of surgery, the second people's hospital of Baiyun district. All patients' parents agreed to the treatment and signed informed consent before injection. The local ethics committees approved the study.

A single well trained and experienced urologist performed all procedures in the operating room. Participants were cleaned with povidone iodine solution and draped in a sterile fashion. Local anesthesia was administered to the dorsal penile nerve and penile ring blocks using $3 \mathrm{mg} / \mathrm{kg}$ of $1 \%$ lidocaine. The conventional circumcision procedure was standardized according to the standard procedure [2]. Circumcision stapler (Wuhu SNNDA Medical Treatment Appliance Technology Co., LTD., Wuhu City, China) was performed as previously described [3]. Circumcision stapler consists of an inner and an outer ring, a silicone rubber gasket and a fastener [4]. Penile diameter is first measured to determine appropriate ring size. After anesthetic administration the inner ring is placed around the penis to the level of the coronal sulcus. The foreskin is carefully everted over the inner ring. The outer ring is placed over the inner ring to sandwich the foreskin. The outer ring is tightened over the inner ring and the excess foreskin is excised using suture scissors. Three to 5 slits are then made in the foreskin on the underside of the ring using a scalpel blade. These slits are needed to enable the skin to spread as healing occurs and allows cab expansion. The ring is left in place for 1 to 2 weeks and removed at a follow up visit. The outcome included operative time and intraoperative blood loss. Operative time was measured from when the effects of the local anesthesia took hold until the end of surgery. Intraoperative blood loss was estimated as follows: soaked $4 \mathrm{~cm} \times$ $4 \mathrm{~cm}$ gauze had an average carrying capacity of $2.85 \mathrm{ml}$ blood.

$\mathrm{t}$-Test was used to compare operative duration, blood loss volume between experiment group and control group. A P value of 0.05 was considered statistically significant. Statistical analyses were performed with SPSS 13.0 software (SPSS, Inc., Chicago, IL).

\section{Results}

40 children completed the trail for final analysis. 20 cases were in experiment group with mean age 6.8 (5 - 11) years old, mean weigh $24.05(22$ - 41) kg; 20 cases were in control group with mean age 6.6 (5 - 10) years old, mean weigh 23.68 (20 - 39) $\mathrm{kg}$. There was no significant difference for baseline data. Table 1 showed significant difference presented in operative time $(5.35 \mathrm{~min}$ vs $30.30 \mathrm{~min}, \mathrm{P}<0.05)$ and intraoperative blood loss $(2.56 \mathrm{ml}$ vs $10.40 \mathrm{ml}, \mathrm{P}<0.05)$ between the 
Table 1. Operative time and blood loss between the two groups.

\begin{tabular}{cccc}
\hline Outcome & Experiment group $(\mathrm{n}=20)$ & Control group $(\mathrm{n}=20)$ & P value \\
\hline Operative time $(\mathrm{min})$ & $5.35 \pm 1.38$ & $30.30 \pm 5.32$ & $<0.05$ \\
blood loss $(\mathrm{ml})$ & $2.56 \pm 0.38$ & $10.40 \pm 1.35$ & $<0.05$ \\
\hline
\end{tabular}

two groups. No children in either group complained a major complication, such as repeat operative procedure, infection or bleeding requiring admission.

\section{Discussion}

To treat redundant foreskin and phimosis with circumcision has been accepted and applied by urologist around the world. Many studies have shown that male circumcision shows potential benefits to the health of the man and his female partner. Although traditional circumcision is the simplest surgery in urology, and can be operated by interns under instruction, it also has drawbacks. It is time and effort consuming, and may cause some bleeding.

Our present trail also demonstrated that circumcision staplers should be the most advanced surgical procedure to treat redundant foreskin and phimosis in children at the present time [5]. The reasons we analyzed were: 1) compared the traditional procedure, the operative time is significant shorter in experiment group (5.35 min vs $30.30 \mathrm{~min}, \mathrm{P}<0.05$ ); 2) bleeding is minimal in experiment group $(2.56 \mathrm{ml}$ vs $10.40 \mathrm{ml}, \mathrm{P}<0.05)$.

In our experience, the learning curve circumcision staplers were short. However, some empirical points should be noted. Firstly, the preoperative evaluation is very important. Concealed penis, webbed penis and hypospadias need to be excluded. Secondary, appropriate model size should be selected. If the size is not chosen properly, pain, notable edema, or difficult post-operative healing may easily occur. Thirdly, the inner layer of the foreskin needs to be reserved properly. Too much inner layer can easily cause penile edema, whereas too little may cause over short foreskin and pain during erection. Finally, the ring removal time is also very important. According to published literature, the rings are typically removed on weeks 1 - 2 after operation [6]. In our study, the optimal time was more than 2 weeks postoperation because more delayed ring removal lead to the more complete healing and the more alleviated edema.

\section{Conclusion}

To sum up, circumcision staplers are superior to conventional circumcision for the advantages of shorter operation time and fewer blood losses. Preoperative evaluation, appropriate model size, appropriate inner layer of the foreskin and appropriate ring removal time were very important for children preformed circumcision staplers.

\section{Conflicts of Interest}

The authors declare no conflicts of interest regarding the publication of this paper. 


\section{References}

[1] Kuehhas, F.E., Miernik, A., Weibl, P., et al. (2013) Incidence of Balanitis Xerotica Obliterans in Boys Younger than 10 Years Presenting with Phimosis. Urologia Internationalis, 90, 439-442. https://doi.org/10.1159/000345442

[2] Bailey, R.C., Moses, S., Parker, C.B., et al. (2007) Male Circumcision for HIV Prevention in Young Men in Kisumu, Kenya: A Randomised Controlled Trial. Lancet, 369, 643-656. https://doi.org/10.1016/S0140-6736(07)60312-2

[3] Cheng, Y., Peng, Y.F., Liu, Y.D., et al. (2009) A Recommendable Standard Protocol of Adult Male Circumcision with the Chinese Shang Ring: Outcomes of 328 Cases in China. National Journal of Andrology, 15, 584-592.

[4] Peng, Y.F., Cheng, Y., Wang, G.Y., et al. (2008) Clinical Application of a New Device for Minimally Invasive Circumcision. Asian Journal of Andrology, 10, 447-454. https://doi.org/10.1111/j.1745-7262.2008.00411.x

[5] Barone, M.A., Li, P.S., Awori, Q.D., et al. (2014) Clinical Trials Using the Shang Ring Device for Male Circumcision in Africa: A Review. Translational Andrology and Urology, 3, 113-124.

[6] Barone, M.A., Awori, Q.D., Li, P.S., et al. (2012) Randomized Trial of the Shang Ring for Adult Male Circumcision with Removal at One to Three Weeks: Delayed Removal Leads to Detachment. Journal of Acquired Immune Deficiency Syndromes, 60, e82-e89. https://doi.org/10.1097/QAI.0b013e31824ea1f2 